\title{
MIELOPATIAS POR HTLV-1 NA CIDADE DE SALVADOR, BAHIA
}

\author{
AILTON MELO, IRENIO GOMES, KILMA MATTOS
}

\begin{abstract}
RESUMO - Paraparesia espástica progressiva associada a HTLV-1 constitui-se em uma patologia com características endêmicas em várias regiōes do Brasil. Em Salvador, 102 pacientes com mielopatias de diversas etiologias foram triados para HTLV-I/II com ELISA e Western blot em quatro hospitais gerais que assistem a população de baixa renda. Foram encontrados 36 pacientes com mielopatia associada a HTLV-I/II, o que está de acordo com a elevada prevalência dessa patologia em Salvador. Todos os pacientes com infecção pelo HTLV-I/ II apresentavam paraparesia espástica progressiva, bexiga neurogênica associada, a graus variáveis de comprometimento sensitivo superficial e/ou profundo e síndrome do neurônio motor inferior. O exame de LCR mostrou pleocitose linfocitária com aumento moderado de gama-globulinas e a ressonância magnética mostrou graus variáveis de lesões periventriculares e subcorticais associadas ou não a atrofia da medula espinal torácica. $\mathrm{O}$ exame neurológico e os dados de ressonância magnética sugerem que os pacientes com comprometimento neurológico por HTLV-I podem estar acometidos por graus variáveis de leucoencefalomieloneuropatia.
\end{abstract}

PALAVRAS-CHAVE: HTLV-I, paraparesia espástica tropical, TSP HAM, leucoencefalomieloneuropatia.

\section{HTLV-I associated myelopathy in the city of Salvador, Bahia (Brazil)}

SUMMARY - Chronic myelopathy associated with human T-lymphotropic virus type I (HTLV-I) has been described in several endemic areas in Brazil. In Salvador, 102 patients with myelopathy were screened for HTLV-I/II by ELISA and Western blot assays. We found 36 patients with HTLV-I/II associated myelopathy confirming the high prevalence of HAM in Salvador. The initial complaint of our patients were urinary urgency, back pain and progressive unsteadiness on walking. On examination all of them had a spastic paraparesis, variable degrees of lower motor neuron syndrome, deep and superficial sensitive syndrome. MRI analysis revealed lesions in the periventricular white matter in addition to atrophy of the thoracic spinal cord. Clinical and magnetic resonance findings reveal that the inflammatory lesions of HAM involve not only the spinal cord but also the brain and peripheral nervous system.

KEY-WORDS: HTLV-I, myelopathy, tropical spastic paraparesis, TSP, HAM, leukoencephalomyeloneuropathy.

As mielopatias e meiloneuropatias crônicas de etiologia indeterminada são de ocorrência comum em Neurologia e assumiram diversas classificações que foram se modificando com o avanço das técnicas diagnósticas. A paraparesia espástica tropical (TSP) constitui grupo de mielopatias e mielorradiculopatias, de expressão clínica e etiológica variável de acordo com a região em que são estudadas $^{23}$. Fatores genéticos, ambientais, tóxicos e nutricionais são comumente relacionados como causa de $\mathrm{TSP}^{23}$. O quadro neurológico desse grupo de patologias é caracterizado por acometimento bilateral e simétrico dos tratos piramidais, que comprometem os membros inferiores, associado a disfunção vesical, impotência e obstipação ${ }^{13,21}$. A associação entre paraparesia espástica tropical e o vírus T linfotrópico adulto (HTLV-I) foi inicialmente demonstrada em 1985, em estudo realizado por Guy De-Thé e col. ${ }^{5}$ na Martinica, em que encontraram sorologia positiva para HTLV-I em 59\%

Unidade de Neuroinfectologia, Universidade Federal da Bahia (UFBA). Aceite: 4-dezembro-1993.

Dr. Ailton Melo - Departamento de Neuropsiquiatria, Faculdade de Medicina, UFBA - Av. Reitor Miguel Calmon s/n - 40110-100 Salvador BA - Brasil. 
de pacientes com TSP. Após essa descoberta inicial, anticorpos para HTLV-I têm sido encontrados, no soro e no líquido cefalorraqueano (LCR) de pacientes com TSP em várias regiões do mundo, principalmente na Jamaica, Colômbia, Ilhas Seychelles, Japão e Estados Unidos ${ }^{6,21,22,28}$. Um estudo nacional realizado no Japão e concluído em 1989, revelou a existência de 700 casos de HAM, dos quais $25 \%$ tiveram como causa transfusão sanguínea ${ }^{18}$. No Brasil, relatos de pacientes com sorologia positiva para HTLV-I têm-se tornado cada vez mais frequentes assumindo a doença, em algumas cidades, proporções de endemia ${ }^{2,3,15,16}$.

Neste estudo descrevemos o envolvimento neurológico em 36 pacientes com diagnóstico de mielopatia associada a HTLV-I/II, discutimos o comprometimento global do sistema nervoso nessa infecção e o provável caráter sistêmico dessa patologia.

\section{MÉTODO}

Salvador, capital do estado da Bahia, é cidade litorânea de aproximadamente 2,3 milhões de habitantes, cuja população foi formada a partir de mistura multirracial, na qual predominaram negros do leste da África (Senegal e Benin) e portugueses.

Durante período de 22 meses (novembro-1990 a junho-1992) foram estudados 102 pacientes com mielopatias não traumáticas e não tumorais, atendidos em quatro hospitais gerais da cidade de Salvador (Hospital Sto. Antonio, Hospital Couto Maia, Hospital Unversitário Prof. Edgard Santos e Hospital Geral do Estado). Os pacientes eram referidos à Unidade de Neuroinfectologia/UFBA, pelo médico responsável. Um membro da Unidade de Neuroinfectologia atendia o paciente em ambulatório ou durante sua internação no hospital de origem; todos os pacientes com mielopatias ou mieloneuropatias crônicas progressivas eram inicialmente submetidos a ficha-protocolo que constava de: questionário epidemiológico com a finalidade de investigar procedência, hábitos de vida, doenças ou recepção prévia de derivados de sangue; exame neurológico; mielografia ou ressonância magnética (RM) de coluna torácica. No LCR foi feita análise de: células; proteínas; eletroforese de proteínas; reações imunológicas para cisticercose, sífilis, toxoplasmose e esquistossomose. Esses exames foram feitos em um único laboratório com técnicas idênticas. Amostras de soro e LCR foram triadas para HTLV-I utilizando-se ELISA. Os casos positivos foram posteriormente submetidos a Western blot. Os pacientes eram considerados positivos quando apresentavam anticorpos no soro e/ou LCR tanto para p24 como para p21E, de acordo com as recomendações do American Health Service para técnicas de laboratório ${ }^{20}$. Os pacientes com anticorpos para HTLV-I/II eram submetidos a RM de coluna e crânio; foi possível a realização desses exames em apenas 19 pacientes de acordo com técnica já descrita.

\section{RESULTADOS}

Características demográficas: $72 \%$ dos casos ocorreram em mulheres (26/36). A faixa etária dos pacientes variou de 8 a 82 anos, média de 42 anos nas mielopatias em geral e de 18 a 71 anos (média de 45,8 anos) nas mielopatias por HTLV-I. Houve história prévia de transfusão sanguínea em 6 pacientes. Apenas 3 pacientes tinham história de promiscuidade, caracterizada, por nosso grupo, por mais de 5 parceiros em um ano (Tabela 1).

Tabela 1. Fatores de risco identificados.

\begin{tabular}{lcc}
\hline Fatores de risco & $\begin{array}{c}\text { Número de } \\
\text { pacientes }\end{array}$ & $\%$ \\
\hline Drogas endovenosas & 0 & 0 \\
Anticorpo positivo para HIV & 3 & 8 \\
Prostituição & 2 & 6 \\
Parceiros em grupo de risco & 1 & 3 \\
Transfusão sanguínea & 6 & 17 \\
Homossexualismo & 1 & 3 \\
Promiscuidade & 2 & 6 \\
\hline
\end{tabular}

Características clínicas: A queixa inicial mais frequente era fraqueza progressiva nos membros inferiores (29/36), seguida de dor lombar (18/36) e urgência miccional (15/36). Foram observados dois tipos de progressão da mielopatia. O mais frequente (25/36) apresentava progressão lenta e gradual; o menos frequente (11/36) apresentava progressão mais rápida, atingindo comprometimento severo da força muscular em aproximadamente dois anos. Com exceção de dois pacientes, todos relataram assimetria da força muscular nos membros inferiores (Tabela 2).

Avaliação radiológica: Foram realizadas mielografias em 17 pacientes, que não mostraram qualquer alteração; 19 pacientes foram avaliados com RM de crânio e coluna (Tabela 3). 
Tabela 2. Resumo do comprometimento neurológico em 36 pacientes com HAM/TSP.

\begin{tabular}{|c|c|c|}
\hline Comprometimento Neurológico & $\mathrm{N}^{\circ}$ de pacientes & $\%$ \\
\hline \multicolumn{3}{|l|}{ Exame psíquico } \\
\hline Normal & 36 & 100 \\
\hline \multicolumn{3}{|l|}{ Motricidade membros inferiores } \\
\hline Fraqueza & 36 & 100 \\
\hline Hiperreflexia patelar & 36 & 100 \\
\hline Hiporreflexia aquileu & 8 & 22 \\
\hline Espasticidade & 36 & 100 \\
\hline Babinski & 29 & 81 \\
\hline Atrofia de quadriceps & 8 & 22 \\
\hline Cãimbras & 8 & 22 \\
\hline \multicolumn{3}{|l|}{ Motricidade membros superiores } \\
\hline Fraqueza & 8 & 22 \\
\hline Hiperreflexia & 16 & 44 \\
\hline Sinal de Hoffmann & 13 & 36 \\
\hline \multicolumn{3}{|l|}{ Sensibilidade membros inferiores } \\
\hline - comprometimento da sensibilidade superficial & 36 & 100 \\
\hline - comprometimento da sensibilidade profunda & 4 & 11 \\
\hline Impotência & 32 & 89 \\
\hline Diminuição da libido & 30 & 83 \\
\hline Urgência miccional ou incotinência urinária & 36 & 100 \\
\hline Obstipação & 32 & 89 \\
\hline Lombalgia & 32 & 89 \\
\hline
\end{tabular}

Tabela 3. Resumo das alterações encontradas no exame de ressonância magnética de 19 pacientes com HAM/TSP.

\begin{tabular}{lcc}
\hline Alteração & Número & $\%$ \\
\hline Comprometimento encefálico & 11 & 57,8 \\
- Periventricular & 2 & 10,5 \\
- Subcortical & 3 & 15,7 \\
- Periventricular/subcortical & 6 & 31,5 \\
$\begin{array}{l}\text { Diminuição do calibre da } \\
\text { medula espinal }\end{array}$ & 7 & 36,8 \\
$\begin{array}{l}\text { Comprometimento medular e } \\
\text { encefálico }\end{array}$ & 6 & 31,5 \\
\hline
\end{tabular}

Avaliação laboratorial: A análise do LCR mostrou aumento de celularidade em 24 pacientes. A variação no número de células foi de 1 a 40 por $\mathrm{mm} 3$. Em todas as amostras de LCR examinadas houve predomínio de linfócitos. A eletroforese de proteínas do LCR evidenciou aumento de albumina em 8 pacientes e elevação de gamaglobulinas em 29. Anticorpos para HIV estavam presentes em 2 pacientes; 1 paciente apresentava reação positiva para esquistossomose no LCR.

\section{COMENTÁRIOS}

As mieloneuropatias tropicais constituemse em um dos grandes desafios neurológicos devido, principalmente, ao número de pacientes cujo diagnóstico etiológico da patologia é inferido, mas dificilmente determinado de forma precisa. 
Tabela 4. Exame do LCR dos pacientes com HAM/TSP.

\begin{tabular}{lc}
\hline Celularidade & $1,0-40$ células \\
Pleocitose & $22(73,3 \%)$ \\
Predominância de linfócitos & $(100 \%)$ \\
Aumento de gama-globulinas & $11(36,1 \%)$ \\
Aumento de albumina & $09(25,0 \%)$ \\
\hline
\end{tabular}

Após a descoberta da associação entre paraparesia espástica tropical e infecção pelo HTLV-I tem-se observado que, no Brasil, grande número de mielopatias progressivas não tumorais apresenta sorologia positiva para HTLV-I ${ }^{3,13}$. Na Bahia observa-se, na população geral de Salvador, prevalência de $1,8 \%$ de anticorpos positivos para HTLV-I no soro ${ }^{16}$. Em pacientes não selecionados, de um hospital que assiste a população de baixa renda, a prevalência aumentou para $19,4 \%$ e, em pacientes com SIDA, para $22,7 \%^{16}$. A frequência de pacientes com HTLV-I observada neste estudo

confirma dados anteriores publicados por Meireles et al. ${ }^{13}$, que encontraram $22 \%$ de HAM em pacientes com TSP admitidos em um hospital geral. Posteriormente Lessa et al. ${ }^{4}$, em estudo casocontrole realizado em Salvador, verificaram risco relativo estimado de 9,0, confirmando a associação de HTLV-I e mielopatia. Os resultados obtidos por Lessa et al. apresentam risco relativo estimado quatro vezes menor que o obtido por Roman et al. ${ }^{21}$, o que se deve provavelmente a diferentes critérios metodológicos utilizados. A frequência de HAM em pacientes com paraparesia progressiva encontrada neste estudo está de acordo com o observado em áreas tropicais de alta endemicidade, como Martinica e Rio de Janeiro ${ }^{2,5}$. A análise do LCR dos nossos pacientes, como demonstrado previamente, revela na maioria dos casos pleocitose de predominância linfocitária e aumento de proteínas com elevação de albumina e gama-globulina ${ }^{17,26}$. Ao contrário de estudos realizados na Jamaica, Tumaco e Rio de Janeiro ${ }^{2,22,23}$, não foram encontrados pacientes com sorologia positiva para sífilis no LCR e sangue.

A transmissão sexual do homem para a mulher e o aleitamento materno parecem constituir-se nas principais vias de transmissão nos pacientes estudados, concordando com dados de outros autores ${ }^{2,7}$. $O$ grau de promiscuidade em nossa amostra foi baixo e a transmissividade por transfusão sanguínea, ainda que em menor percentagem que a descrita por autores japoneses ${ }^{7}$, se constitui em índice elevado, o que reflete a alta endemicidade da doença em Salvador.

A alta prevalência de mielopatias infecciosas na Bahia, principalmente devido a esquistossomose ${ }^{19}$, não nos permite inferir apenas com dados clínicos e sorológicos um diagnóstico etiológico dessas enfermidades. Como pacientes com mielopatias devido a outras patologias podem ter anticorpos circulantes para HTLV-I, é nossa opinião que o diagnóstico de HAM só deverá ser feito quando o paciente, além da sorologia positiva, apresentar o conjunto de sinais e sintomas que caracteriza o envolvimento neurológico pelo HTLV-I associado a um LCR com padrão característico. $\mathrm{Na}$ maioria dos pacientes encontram-se também dados clínicos e laboratoriais do envolvimento sistêmico da doença, o que permite maior precisão diagnóstica.

A análise de ressonância magnética de crânio e coluna realizada nos pacientes com HTLV-I/ II mostrou presença de lesões periventriculares e subcorticais em 5 pacientes, comprovando dados anteriores de outros autores ${ }^{8,14,25}$. O registro anatomopatológico de comprometimento da medula espinal em pacientes com HAM está de acordo com nossa descrição de atrofia da medula espinal torácica, observado à RM em $36,8 \%$ dos pacientes analisados, a qual se constitui em característica importante para o suporte diagnóstico do envolvimento do sistema nervoso pelo HTLV-I. Em nossa opinião, o vírus atua sobre tratos espinais produzindo comprometimento da substância branca e, posteriormente, lesão axonal que se traduz macroscopicamente como redução do diâmetro da medula e microscopicamente por infiltrado inflamatório linfocitário perivascular com áreas de gliose, conforme descrição anátomo patológica ${ }^{1}$. A abolição do reflexo aquileu encontrada em nossos pacientes e nos de Roman et al. em Tumaco ${ }^{21}$ está de acordo com o relato de Said et al. ${ }^{24}$ que encontraram infiltração linfocitária em nervos periféricos de um paciente com HAM e com resultados 
de estudos eletromiográficos que mostram neuropatia periférica em $25 \%$ desses pacientes ${ }^{28}$. No Japão, ao contrário, os pacientes com HAM apresentam apenas leucoencefalomielopatia sem evidências clínicas ou eletrofisiológicas de comprometimento de nervos periféricos ${ }^{8}$. Apesar do objetivo desse estudo estar relacionado às alterações neurológicas dos pacientes com HAM, dados da Unidade de Neuroinfectologia da UFBA $^{11}$ e de outros autores ${ }^{9}$ deixam claro que essa é uma patologia de caráter sistêmico e, portanto, faz-se necessário analisar não apenas o comprometimento neurológico mas, também, os diversos sistemas que comumente estão envolvidos nos pacientes com essa infecção. Ao exame clínico minucioso (com ênfase nas articulações, pulmões e olhos, entre outros) deve se seguir esfregaço de sangue periférico com o objetivo de identificar a presença de linfócitos multilobulados e raio $\mathrm{X}$ de tórax em incidência póstero-anterior para verificar sinais incipientes de fibrose intersticial, como o descrito por Mattos et al. ${ }^{12}$. Considerando a alta prevalência de infecção por HTLV-I em países da África e da América Latina e o grande número de pacientes com paraparesia espástica progressiva de etiologias tóxica, carencial e infecto-parasitária, é importante a criação de fluxogramas para normatizar o diagnóstico e a conduta clínica desse grupo de patologias.

\section{REFERÊNCIAS}

1. Akizuki S, Nakazato O, Higuchi Y, Tanabe K, Setoguchi M, Yoshida S, Miyazaki Y, Yamamoto S, Sudou S, Sannomiya K, Okajima T. Necropsy findings in HTLV-I associated myelopathy. Lancet 1987, 1: 156-157.

2. Araújo AQC, Alfonso CR, Schor D, Leite AC, Andrade-Serpa MJ. Clinical and demographic features of HTLV-I associated myelopathy/tropical spastic paraparesis (HAM/TSP) in Rio de Janeiro, Brazil. Acta Neurol Scand 1993, 88: 59-62.

3. Araújo AQC, Alfonso CR, Schor D, Andrade-Serpa MJ. Spastic paraparesis of obscure origin: a case control study of HTLV-I positive and negative patients from Rio de Janeiro, Brazil. J Neurol Sci 1993, 116: 165-169.

4. Bhigjee Al, Bill PLA, Wiley CA, Windsor IM, Mathias DA, Amenomori T,Wachsman W, Moorhouse D. Peripheral nerve lesions in HTLV-I associated myelopathy (HAM/TSP). Muscle Nerve 1993, 16: 21-26.

5. Gessain A, Vernant JC, Maurs L, Barin F, Gout O, Calender A, De Thé G. Antibodies to human T-lymphotropic virus type-1 in patients with tropical spastic paraparesis. Lancet 1985, 2: 407-410.

6. Janssen RS, Kaplan JE, Khabbaz RF et al. - HTLV-I associated myelopathy/tropical spastic paraparesis in the United States. Neurology 1991,41: 1355-1357.

7. Kajiyama W, Kashiwagi S, Ikematsu H, Hayashi J, Nomura H, Okochi K. Intrafamilial transmission of adult T-cell leukemia virus. J Infect Dis 1986, 154: 851-857.

8. Kira J, Minato S, Itoyama Y, Goto I, Kato M, Hasuo K. Leukoencephalopathy in HTLV-I associated myelopathy: MRI and EEG data. J Neurol Sci 1988, 87: 221-232.

9. Kuroda Y, Fukuoka M, Endo C, Matsui M, Kurohara K, Kakigi R, Tokunaga O. Occurrence of biliary cirrhosis, CREST syndrome and Sjogren's syndrome in a patient with HTLV-I associated myelopathy. $J$ Neurol Sci 1993, 116: 47-51.

10. Lessa I, Moraes D, Meireles A, Melo A. HTLV-I and myelopathy in Salvador (Northeastern Brazil): a case control study. Arq Neuropsiquiatr 1993, 51: 447-451.

11. Mattos K, Queiroz C, Peçanha-Martins AC, Publio L, Melo A. Lymphocyte alveolitis in HAM/TSP patients. Arq Neuropsiquiatr 1993, 51: 134-136.

12. Mattos K. Estudo do lavado broco-alveolar em portadores de mielopatia associada a HTLV-I. Tese de Mestrado, Universidade Federal da Bahia, Salvador, 1993.

13. Meireles A, Moreira ED Jr, Moreno-Carvalho OA, Badaró R, Melo A. HTLV-I associated myelopathy in Salvador (Northeastern-Brazil). Arq Neuropsiquiatr 1992, 50: 189-190.

14. Melo A, Moura L, Rios S, Machado M, Costa G. Magnetic resonance imaging in HTLV-I associated myelopathy. Arq Neuropsiquiatr 1993, 51: 329-332.

15. Moreira ED Jr, Harrington W Jr, Ribeiro TT, Melo A, Brites C, Badaró R, Swanson P, Lee H. HTLV-II and a new endemic area for HTLV-I in Brazil. Rev Soc Bras Med Trop 1992, 25: 141-143.

16. Moreira ED Jr, Ribeiro TT, Swanson P, Sampaio C, Melo A, Brites C, Badaró R, Toedter G, Lee H, Harrington W Jr. Seroepidemiology of human T-cell lymphotropic virus type I/II in Northeastern Brazil. J AIDS 1993, p 959-963.

17. Moreno-Carvalho OA, Santos JI, Di Gredici G, Galvão B. Evidence of preferencial females prevalence of HTLV-I associated tropical spastic paraparesis in Bahia, Brazil. Arq Neuropsiquiatr 1992, 50: 183-188.

18. Osame M, Janssen RS, Kubota H, Nishitani H, Igata A. Nationwide survey of HTLV-I associated myelopathy in Japan: association with blood transfusion. Ann Neurol 1990, 28: 50-56. 
19. Peregrino AJP, Oliveira SP, Porto CA, Santos LA, Menezes EE, Silva AP, Brito Al, Pinheiro SP, Pinheiro S, Dias AB. Meningomieloradiculite por Schistosoma mansoni. Arq Neuropsiquiatr 1988, 46: 49-60.

20. Public Health Service Working Group (FDA/CDC/NIH). Licensure of screening tests for antibody human T lymphotropic virus type I. Morbid Mortal Weekly Republic 1988, 37: 736-747.

21. Roman GC, Spencer PS, Schoenberg BS, Madden DL, Sever JL, Hugon J, Ludolph A, Spencer PS. Tropical spastic paraparesis in the Seychelles islands. Neurology 1987, 37: 1323-1328.

22.Roman GC. The neuroepidemiology of tropical spastic paraparesis. Ann Neurol 1988, 23 (Suppl) 113-130. 23. Roman GC. Tropical spastic paraparesis and HTLV-I myelitis. In Vinken PJ, Bruyn GW, Klawans HL (eds). Handbook of Clinical Neurology, Volume 56. Amsterdam: Elsevier, 1989, p 525-542.

24. Said G, Goulon-Groean C, Lacroix C, Fève A, Descamps H, Fouchard M. Inflammatory lesions of peripheral nerve in a patient with human T-lymphotropic virus type 1 associated myelopathy. Ann Neurol 1988, 24: 275-277.

25. Sheremata WA, Quencer R, Gatti E et al. Magnetic resonance imaging of tropical spastic paraparesis. Neurology 1987, 37 (Supp 1): 322.

26. Spina-França A, Livramento JA, Machado LR, Gomes HR, Vianna LS, Castro LHM, Nobrega JPS, Bacheschi LA. HTLV-I antibodies in serum and cerebrospinal fluid in tropical spastic paraparesis in Brazil. Arq Neuropsiquiatr 1990, 48: 441-447.

27. Swieten JC, Geyskes GG, Derix MMA. Hypertension in the elderly is associated with white matter lesions and cognitive decline. Ann Neurol 1991, 30: 825-830.

28. Zaninovic V, Arango C, Biojo R, Mora C, Rodgers-Johnson P, Concha M, Corrai R, Barreio P, Borriro I, Garruto RM, Gibbs CJ Jr, Gajdusek DC. Tropical spastic paraparesis in Colombia. Ann Neurol 1988, 23 (Suppl): S127-132. 